\title{
DAS RESTRIÇÕES À LIBERDADE DE EXPRESSÃO FRENTE À VIOLAÇÃO DOS DIREITOS DAS MINORIAS SEXUAIS PELO DISCURSO DE ÓDIO
}

\author{
Caio Eduardo Costa Cazelatto ${ }^{1}$ \\ Valéria Silva Galdino Cardin ${ }^{2}$
}

RESUMO: Limitar a liberdade de expressão sempre foi alvo de constantes discussões acadêmicas. Ao se permitir que o conteúdo do pensamento seja externado livremente, dá-se margem à propagação de condutas que violam outros direitos, como o discurso de ódio homofóbico, o qual ofende os direitos das minorias sexuais, como a vida, a honra, dentre outros. Diante disso, a presente pesquisa analisou, por meio do levantamento bibliográfico, quais os possíveis limites jurídicos entre a liberdade de manifestação do pensamento e a conduta discursiva de cunho homofóbico. Para isso, explorou-se a autorização constitucional para sua limitação, bem como o princípio da proibição do abuso de direitos.

PALAVRAS-CHAVE: Direitos da personalidade; Discurso de ódio; Liberdade de expressão; Minorias sexuais.

\section{RESTRICTIONS ON FREEDOM OF EXPRESSION REGARDING THE VIOLATION OF THE RIGHTS OF SEXUAL MINORITIES WHEN USING HATE SPEECH}

ABSTRACT: The limits of freedom of expression are the subject of constant academic discussions. By allowing freedom of expression, we also allow for the propagation of conducts that violate other rights, such as homophobic hate speech, which offends the rights of sexual minorities, with regard to their life and honor, among others. Given this, the present research analyzed through a bibliographical survey, what the possible legal limits are between the freedom of expression and the discursive conduct of a homophobic nature. For this, the constitutional authorization for its limitation was explored, as well as the principle of prohibition of abuse of rights.

KEYWORDS: Personality rights; Hate speech; Freedom of expression; Sexual Minorities.

\section{INTRODUÇÃO}

\footnotetext{
${ }^{1}$ Mestre em Ciências Jurídicas pelo Centro Universitário de Maringá (UNICESUMAR); Bacharel em Direito pela Universidade Estadual de Maringá (UEM); Advogado; E-mail: caio.cazelatto@hotmail.com 2 Pós-doutora em Direito pela Universidade de Lisboa; Doutora e mestre em Direito das Relações Sociais pela Pontifícia Universidade Católica de São Paulo (PUCSP); Docente da Universidade Estadual de Maringá e no Programa de Pós-graduação em Ciências Jurídicas pelo Centro Universitário de Maringá (UNICESUMAR); Pesquisadora pelo ICETI; Advogada no Paraná; E-mail: valeria@galdino.adv.br
} 
A liberdade de externar os pensamentos por meio de opiniões, sensações, emoções, enfim tudo aquilo que o indivíduo acredita ser relevante para a sua autoconstrução, bem como para a intervenção no espaço ao qual está inserido e, consequentemente, para influenciar as pessoas ao seu redor, são atividades imprescindíveis para a realização plena da personalidade humana, como também é um selo distintivo das atuais sociedades democráticas, funcionando como um termômetro do regime democrático.

É por meio da linguagem que o ser humano apresenta o que pensa, o que se sente e o que acredita. Contudo, é somente com a expressão que a linguagem toma forma, tornando-se ambas praticamente indissociáveis.

Essa interação viabiliza a integração comunicacional do sujeito em suas mais variadas esferas institucionais, como na família, no trabalho, no lazer e no esporte, dentre outros, afinal, seria ilógico, incalculável e um obstáculo para a progressão da humanidade que todo o conteúdo do pensamento fosse restrito e oculto no intelecto.

Ocorre que a propagação de ideias sofre vedações expressas ou implícitas tanto na Constituição Federal quanto nas leis infraconstitucionais, como por exemplo: o caso das autorizações constitucionais ou o princípio da proibição do abuso dos direitos fundamentais ou da personalidade.

Ao ser difundida de maneira irresponsável, a liberdade de expressão viola ou impede o exercício de outros direitos como o direito à vida, à honra, a liberdade em sentido amplo, dentre outros, isso porque ela pode se revestir como um ato discursivo de ódio, assumindo uma finalidade diversa do direito à livre manifestação de ideias.

Nesse cenário está o discurso de ódio homofóbico, que é direcionado às minorias sexuais. Trata-se de uma conduta que visa, exclusiva e injustificavelmente, hostilizar, inferiorizar e combater os direitos da comunidade LGBT, a qual se encontram inseridas as pessoas gays, lésbicas, bissexuais, pansexuais, transgêneros e todas as demais expressões da sexualidade humana que não correspondam ao modelo hetero-cis-sexual, isto é, que não sejam a heterossexual e a cisgênero.

Por ser um ato que, ao ser assimilado e difundido como correto, potencializa a prática da homofobia, acarretando inúmeras violações de direitos das minorias sexuais, a restrição da livre propagação de pensamentos deve ser melhor analisada. Para tanto, a presente pesquisa visa esclarecer as seguintes indagações: A liberdade de expressão é um direito absoluto? Há 
restrições ao seu exercício? Quais as diferenças entre a liberdade de manifestação de ideias e o discurso de ódio? O que é o discurso de ódio homofóbico? Quais os impactos dos atos discursivos de ódio contra os direitos das minorias sexuais?

Para responder a estes questionamentos, a metodologia empregada compreenderá, por meio da revisão narrativa, o levantamento bibliográfico, que consiste em analisar, de forma critica, o que já foi produzido e registrado acerca do tema em obras doutrinárias, periódicos, legislação, reportagens e documentos eletrônicos.

\section{DAS LIMITAÇÕES JURÍDICAS À LIBERDADE DE EXPRESSÃo}

Em que pese a inestimável importância que permeia a liberdade de expressão, seja por esta ser um dos pilares do Estado Democrático de Direito, seja por esta garantir o desenvolvimento da autonomia e da personalidade humana, é certo que, assim como qualquer outro direito, seu exercício não é absoluto, nem ilimitado, muito menos é axiologicamente superior a outros direitos fundamentais ou da personalidade.

Ao optar por viver em uma sociedade política e juridicamente organizada, o ser humano dispôs, por meio do pacto social, de parte da soberania de sua liberdade individual ao Estado, para que este impusesse limites e a protegesse, visando, assim, o bem, a harmonia e a vontade geral (ROUSSEAU, 2001, p. 22). De todas as garantias que este "contrato" proporciona às pessoas, a liberdade em expressar as convicções, as opiniões, os sentimentos, os valores e os outros atributos valiosos à condição humana, é a que mais deve ser preservada, por ser, de certa forma, a liberdade que mais se vincula às demais (CUNDARI, 2006, p. 12).

Nesse sentido, Cleide Aparecida Gomes Rodrigues Fermentão sustenta que a liberdade, entendida aqui em sentido amplo, é o resultado da força e da vontade de seu titular e, em virtude deste viver em sociedade, está sujeito a um ordenamento jurídico que impõe um limite para o exercício desse direito, essa delimitação existe em respeito a uma vida social em harmonia (FERMENTÃO, 2009, p. 197).

Essas restrições são mecanismos de organização social responsáveis por assegurarem a efetividade dos demais direitos que possam ser lesados pela prática inconsequente da liberdade de expressão. Assim, é plenamente viável e coerente, conforme Gilberto Haddad Jabur, compreender que a liberdade de pensamento seja inviolável e livre de vigilância externa, por outro lado, a sua externalização ilimitada ao público ocasionaria o distanciamento do 
interesse e do bem coletivo, bem como dos direitos essenciais à própria personalidade, razão pela qual deve ser restringida pelo poder estatal (JABUR, 2000, p. 189).

Já José Celso de Mello Filho defende a liberdade de pensamento como um direito absoluto e insubmisso às restrições impostas pelo ordenamento público, mas concorda que a liberdade de expressar o que se pensa, em virtude de envolver a manifestação de ideias e de crença religiosa, política ou filosófica, sujeita-se ao poder de polícia estatal (MELLO FILHO, 1986, p. 153).

De fato, a liberdade de expressão é incompatível com toda forma de censura prévia, o que “[...] não significa que possa ser tolerada uma liberdade irresponsável. Ao revés, todo abuso deve ser reprimido, pois significa a negação do direito" (COMPARATO, 2007, p. 317). Em virtude disso, é justificável a necessidade de se impor determinadas moderações na atividade do ato de se expressar, buscando a essência da finalidade desse direito, tendo em vista que seria insustentável que seu exercício acarretasse justamente o desrespeito, a fragilização e a violação aos direitos fundamentais e de personalidade, afinal, o limite do direito de cada um é o direito dos outros (TAVARES, 2005, p. 227).

Com efeito, os seres humanos são interdependentes, o que torna impossível assegurar que "[...] a atividade de nenhum homem é tão completamente privada, que nunca venha a obstruir as vidas dos outros de uma forma ou de outra” (BERLIN, 1981, p. 137).

Toda liberdade tem limites lógicos, que estão consubstanciados na própria concepção de liberdade, a qual deverá ter como pressuposto a abstenção em violar direitos de terceiros ou conflitar com os interesses públicos e privados importantes (RAO, 1999, p. 53).

Em outras palavras, o ser humano é livre e tem sua autonomia preservada ao condicionar suas ações aos contornos estipulados pelo ordenamento jurídico, em conformidade com o que afirma Ricardo Luis Lorenzetti:

O exercício da liberdade deriva em uma regra de autonomia que importa a possibilidade de decidir sem condicionamentos externos. Não se trata de decidir sem limites, já que estes existem, e são derivados dos direitos dos outros e dos bens públicos. Trata-se que dentro do espaço de autonomia concedido pelo ordenamento jurídico o sujeito possa decidir por si mesmo (LORENZETTI, 1998, p. 502).

Se de um lado a Constituição Federal protege a liberdade de expressão, por outro, estabelece normas autorizando a relativização desse direito com a sua consequente limitação, como: a vedação do anonimato (art. $5^{\circ}$, inc. IV); a proteção e o respeito do direito de resposta, 
proporcional ao agravo (art. $5^{\circ}$, inc. V); a garantia da inviolabilidade da intimidade, da vida privada, da honra e da imagem (art. $5^{\circ}$, inc. X); a liberdade de exercício de qualquer trabalho, ofício ou profissão, atendidas as qualificações profissionais que a lei estabelecer (art. $5^{\circ}$, inc. XIII); e, oportunamente, a o acesso à informação, resguardado o sigilo da fonte, quando necessário ao exercício profissional (art. $5^{\circ}$, inc. XIV). Apesar disso, não é qualquer expressão que é protegida pelo direito à liberdade de expressão, para tanto, ela deverá ser lícita e o seu objeto compatível com o núcleo essencial desse direito, isto é, com a sua essência.

Logo, toda ação que ultrapassar os limites da esfera da autodeterminação poderá ser um instrumento de repressão. Essa ideia pode ser extraída do próprio texto constitucional, como: a liberdade de manifestação de pensamento não autoriza a calúnia, a difamação ou a injúria; da mesma forma que a liberdade de culto religioso não é compatível com o sacrifício de humanos, ainda que seja previsto em algum ritual religioso. Essas condutas são inadmissíveis, reprovadas jurídica e socialmente, cabendo à intervenção estatal por meio de restrições a essas liberdades (FREITAS; CASTRO, 2013, p. 332).

Considerando que a utilização linguagem pode acarretar em benefício, auxílio ou danos a alguém, a vedação do anonimato tem como objetivo diminuir as possibilidades de que as transgressões contra os direitos à honra, à intimidade, à vida privada e à imagem de terceiros aconteçam de modo inconsequente. É uma forma de garantir a identificação e a responsabilização daquele que emite a opinião ao espaço público (MEYER-PLUFG, 2009, p. $83-85)$.

Ademais, a liberdade de expressão se reveste com mais limitações frente às mensagens que provocam reações de violência, de hostilidade, de desigualdade, de quebra da ordem ou qualquer outra que retire a essência da humanidade de outro indivíduo, rebaixando-o à coisa, a mero ser existencial, sendo seus contornos de restrições conduzidos, neste caso, pela dignidade da pessoa humana (CARDIN; SANTOS, 2014, p. 170 - 171).

Além da autorização constitucional, outro mecanismo de limitação da liberdade de expressão se dá por meio do princípio da proibição de abuso de direitos fundamentais, o qual impõe que nenhum direito fundamental deve ser interpretado no sentido de autorizar o cometimento de condutas que visem à violação de outro direito ou liberdade. Dessa forma, o exercício da liberdade de expressão, enquanto um direito fundamental, não pode ser abusivo para mascarar práticas ilícitas contra direitos ou valores constitucionalmente elencados (MARMELSTEIN, 2011, p. 459), sendo que, em determinados casos, “[...] o ato 
intrinsecamente ilícito pode derivar do exercício de um direito, que ultrapassa seus limites formais" (FIUZA, 2004, p. 243).

Nessa perspectiva, a Declaração Universal dos Direitos Humanos prevê, em seu art. XXX, que nenhuma norma poderá ser interpretada para favorecer que qualquer Estado, agrupamento ou indivíduo recorram a finalidades prejudiciais aos direitos e às liberdades por ela tutelados (UNITED NATIONS HUMA RIGHTS, 1948).

Da mesma forma, o Pacto de San José da Costa Rica apresenta, em seu art. 29, um dispositivo prevendo o princípio da proibição de abuso de direito fundamental, ao sustentar que nenhuma disposição da referida Convenção Internacional poderá ser interpretada no sentido de permitir a qualquer dos Estados-partes, grupo ou indivíduo, suprimir o gozo e o exercício dos direitos e liberdades reconhecidos ou limitá-los em maior medida do que a nela prevista; bem como limitar o gozo e exercício de qualquer direito ou liberdade que possam ser reconhecidos em virtude de leis de qualquer dos Estados-partes ou em virtude de Convenções em que seja parte um dos referidos Estados; excluir outros direitos e garantias que são inerentes ao ser humano ou que decorrem da forma democrática representativa de governo.

Ainda, esse documento internacional disciplina a limitação da liberdade ao dispor que todo ser humano tem deveres para com a família, a comunidade e a humanidade, em que os direitos de cada indivíduo terão seus limites nos direitos dos demais, a fim de se buscar a segurança coletiva e as justas exigências ao bem comum em uma sociedade democrática (ROLIM, 1966). Esses dispositivos indicam a relatividade dos direitos humanos nele elencados, estabelecendo, inclusive, diretrizes hermenêuticas que afastam a invocação de direitos humanos quando tal puder ocasionar a minoração do regime protetivo geral dessa categoria de direitos.

Embora a Constituição Federal não elenque, explicitamente, o princípio da proibição de abuso de direito fundamental, em virtude da internalização do direito internacional dos direitos humanos no ordenamento jurídico brasileiro é possível extraí-lo como implícito no rol dos direitos e garantias fundamentais, podendo ser utilizado para a limitação ou até mesmo a perda total de direitos fundamentais quando se demonstrar o abuso no seu exercício (AMATO, 2013).

Para tanto, George Marmelstein (2011, p. 459 - 460) aponta determinadas situações constitucionais em que está circunscrito, mesmo que implicitamente, o mencionado princípio: é o caso da inviolabilidade do domicílio, o qual poderá ser invadido em caso de flagrante de 
delito. ${ }^{3} \mathrm{Ou}$, ainda, ao que se refere ao sigilo das comunicações, que pode ser interceptado para fins de investigação criminal. ${ }^{4}$ Outro exemplo: a liberdade é protegida, no entanto, pode ser cerceada em caso de prisão por flagrante delito ou por ordem de autoridade judicial competente. ${ }^{5}$

Portanto, os direitos fundamentais não podem ser empregados para fins ilícitos ou como fundamento para a execução de atos moralmente injustificáveis e hostis a outrem, até porque tais visam à promoção do bem-estar e da dignidade da pessoa humana, e não para acobertar práticas que ameacem esses valores, muito menos para gerarem injustiças.

Em âmbito infraconstitucional, o Código Civil brasileiro incorpora o princípio da proibição do abuso de direito, direcionando, em especial, aos direitos de personalidade. Para isso, qualifica, em seu art. 187, como um ato ilícito “[...] o titular de um direito que, ao exercêlo, excede manifestamente os limites impostos pelo seu fim econômico ou social, pela boa-fé ou pelos bons costumes".

O abuso de direito é, para Paulo Nader, uma espécie de ato ilícito, que pressupõe a violação de direito alheio mediante conduta intencional que exorbita o regular exercício de direito subjetivo. No abuso de direito, o agente extrapola, por meio de atos de egoísmo, antissociais, os limites ditados por fins econômicos ou sociais, descumprindo o dever de solidariedade e também o jurídico. (NADER, 2016, p. 616 - 617).

Nesse caso, Taís Carvalho Silva esclarece que a liberdade de expressão, enquanto um abuso de direito, sofre limitações para evitar que sejam disseminadas opiniões com conteúdos inverídicos, injuriosos e sem guardar relação com as ideias ou opiniões que se manifestam, sendo, pois, desnecessária à exposição das mesmas (SILVA, 2012, p. 134 - 135).

Dessa forma, quando o exercício da liberdade de expressão for incongruente com os limites ditados para os seus fins, bem como estiver direcionado para violar ou inviabilizar a atividade de direitos de terceiros, estará revestido como um abuso de direito fundamental e de personalidade, caracterizando-se como um discurso do ódio.

\footnotetext{
3 “Art. $5^{\circ} \mathrm{XI}$ - a casa é asilo inviolável do indivíduo, ninguém nela podendo penetrar sem consentimento do morador, salvo em caso de flagrante delito ou desastre, ou para prestar socorro, ou, durante o dia, por determinação judicial."

4 "Art. $5^{\circ}$ XII - é inviolável o sigilo da correspondência e das comunicações telegráficas, de dados e das comunicações telefônicas, salvo, no último caso, por ordem judicial, nas hipóteses e na forma que a lei estabelecer para fins de investigação criminal ou instrução processual penal."

5 “Art. $5^{\circ}$ LXI - ninguém será preso senão em flagrante delito ou por ordem escrita e fundamentada de autoridade judiciária competente, salvo nos casos de transgressão militar ou crime propriamente militar, definidos em lei."
} 


\section{DO DISCURSO DE ÓDIO HOMOFÓBICO}

Com a complexidade e o estreitamento das relações individuais impulsionados, principalmente, pelas tecnologias informativas, a linguagem se potencializou como um instrumento de poder sobre o controle social, emergindo questões antes não antevistas ou pouco discutidas, como os limites da liberdade de expressão. Liberdade, esta, que permite as pessoas se socorrerem à comunicação e à propagação de seus pensamentos, mas também possibilita à utilização de atos discursivos de ódio, razão pela qual a sua análise transcende a mera interpretação exegética da lei, para se aprofundar na interpretação dos valores assegurados constitucionalmente, como a liberdade, a tolerância, a igualdade, a dignidade e a não discriminação.

Considerado como uma ferramenta de reprodução de ideologias, o discurso de ódio tem suas raízes na terminologia americana hate speech, podendo ser caracterizado como um instrumento que se utiliza da linguagem verbal ou extraverbal, como a fala, os gestos, a música, o cinema, o vídeo, a pintura, a dança, os livros e até o silêncio para transmitir as manifestações de desprezo, de intolerância e de violência (SARMENTO, 2006, p. 208).

Em outras palavras, é um ato de incitação ao ódio, carregado com um conteúdo hostil contra determinados grupos, geralmente contra os grupos vulneráveis ou as minorias sociais, motivadas por preconceitos ligados à etnia, à religião, à idade, à condição financeira, à orientação afetivo-sexual, à identidade de gênero, dentre tantos outros (BRUGGER, 2007, p. $151)$.

São manifestações do pensamento que buscam transmitir e alimentar o ódio, desvalorizando, menosprezando, desqualificando e inferiorizando o ser humano à condição de objeto. Em suma, essas atitudes insuflam o desrespeito pelo diferente. De fato, o ódio social não é apenas o motivo de conflitos entre os indivíduos isoladamente considerados, mas também em sua coletividade, organizados em grupos, em classes ou mesmo enquanto sociedade, caracterizando-se por sua essência de repulsa advinda de razões sociais (SILVEIRA, 2007, p. 80 - 82). É um sentimento que se direciona para além de sua vítima, já que visa disseminar a cultura do medo e do terror para alcançar indivíduos que, ou coadunem com esse posicionamento ou que se sintam ameaçados (MEYER-PLUFG; CARCARÁ, 2014, p. 386). 
Assim, a caracterização do discurso de ódio decorre, como dispõe Alexandre Assunção e Silva, da transgressão dos limites da liberdade de expressão, seja pelo não respeito às restrições impostas expressa ou implicitamente pela Constituição Federal, seja pelo abuso do seu exercício, carregando-o com um conteúdo que vai além da finalidade desse direito (SILVA, 2012, p. $37-43)$.

Em virtude do subjetivismo que perpassa a identificação do discurso de ódio, seus limites com a liberdade de expressão se demonstram, em muitos casos, sutis, dificultando a percepção de seu aspecto agressivo.

De acordo com Meyer-Plufg, este pode ocorrer de modo implícito, velado ou subliminar, também denominado por discurso material, ou de maneira explícita, clara e aparente, também qualificado como discurso formal (MEYER-PLUFG, 2011).

Em que pese a legislação brasileira carecer de uma regulamentação acerca do discurso de ódio, uma das diretrizes para a sua identificação pode se dar por meio do Pacto Internacional sobre Direitos Civis e Políticos, o qual aponta alguns critérios para distinguir o discurso de ódio do simples exercício da liberdade de expressão, quais sejam: conter severa ofensa; possuir a intenção de incitar o ódio; ter a forma de um discurso; ser dirigido ao público em geral ou a um número de indivíduos em um espaço público; conter a probabilidade de ocorrência de dano; ser um dano iminente, visando a possibilidade de identificar a ação e imputar ao emissor do discurso a responsabilidade pelo eventual resultado; e, por fim, estar inserido em um contexto que possibilita verificar se as declarações tem potencial de incitar ódio e gerar alguma ação (BRASIL, 1992).

Para que esse ódio produza efeitos lesivos é necessária a sua externalidade, isto é, sair do plano abstrato do pensamento para o espaço público, o que se dá por meio do discurso (SILVA, 2011, p. 447). Logo, a questão fundamental que permeia essa conduta discursiva é a relação entre o pensar, o falar e o agir. Nessa perspectiva, sua concretização pressupõe a sua publicidade, caso contrário, serão apenas pensamentos, sentimentos e ódio sem o discurso, o que tornaria incabível a sua intervenção por meio de sanções jurídicas ou extrajurídicas.

Para Thiago Dias de Oliva, em que pese o emprego da nomenclatura "discurso", o discurso do ódio deve ser interpretado como um "ato discursivo", uma vez que se estrutura em etapas, passando pela cognição, pela preparação e pela execução. Para ele, nessa categoria estão as expressões escritas, orais e visuais revestidas de conteúdos tanto intimidatório, quanto de 
instigação ao ódio, dirigidos ao fomento da aversão social a membros de um grupo socialmente minoritário (OLIVA, 2015, p. 50 - 51).

Sob o ponto de vista jurídico, há duas correntes doutrinárias opostas que, ou defende o hate speech como um livre desenvolvimento do direito à liberdade de expressão, ou como um abuso deste direito. Seguindo a primeira vertente, Raoul Vaneigem compreende o livre e o amplo exercício da manifestação de expressão como o direito de se expressar a respeito de qualquer assunto, justificando-se que seus limites sejam impostos pelos seus receptores, que deverão avaliar e concordar ou não com o que foi transmitido, razão pela qual essa liberdade não deve ter restrições (VANEIGEM, 2004, p. 99).

Com similar compreensão, John Stuart Mill aponta que todo arranjo social é dirigido, para fins organizacionais e de ordem, por determinadas "verdades", isto é, por postulados aceitos pela (tirania da) maioria. Em conformidade com essa teoria, ao se proteger o direito de se exteriorizar livremente novas "verdades" perante as anteriores, a liberdade de expressão se qualifica como um dever social, tendo em vista que tais são apresentados ao crivo do público para a análise de seus conteúdos. Caso forem coerentes, as pessoas as aceitarão, caso contrário, serão repudiadas, pelo que se justifica nunca censurar esse direito (MILL, 1992, p. 58 - 61). Em outras palavras, em um mercado livre de ideias, as opiniões verdadeiras irão encontrar o apoio da sociedade e prevalecerão sobre as falsas.

Apesar de ser um defensor radical da liberdade, sustentando, inclusive, que o indivíduo deve ser livre para causar danos a si mesmo, John Stuart Mill revela uma única e específica hipótese para limitá-la: a possibilidade de causar danos a outrem, especialmente em casos da liberdade de expressão de um limitar a do outro. Trata-se da aplicação do que ele denomina por harm principle (MILL, 1992, p. 60).

Esse princípio seria plenamente aplicável, por exemplo, se alguém gritasse dissimuladamente, em um auditório lotado, a palavra "fogo". O pânico gerado por essa falsa mensagem causaria um tumulto e, possivelmente, danos a terceiros. Portanto, esta liberdade deve ser limitada, mas não em virtude do que foi dito e, sim, por causa da eminente capacidade de causar ou não danos. Por outro lado, caso nesta mesma situação o público do auditório tivesse condições de observar concretamente que não há fogo, essa expressão seria permitida, mesmo sendo falsa. Isso porque a existência de divergentes opiniões fortalece a sociedade, já que cria 
um pluralismo de ideias em competição, incentivando uma constante evolução intelectual do pensamento e, consequentemente, das pessoas.

Para Ronald Dworkin, as manifestações de expressão que são consideradas ofensivas e detentoras de repúdio por parte da sociedade têm tanto direito de proteção jurídica quanto qualquer outra expressão, isso porque, para ele, os discursos, não importam quais sejam, devem ser combatidos com mais discursos, para que aquele que melhor for argumentado se sobressaia sobre os demais, não necessitando de outras intervenções, como as limitações jurídicas da liberdade de expressão (DWORKIN, 2006, p. 321).

Sob a mesma ótica, Alexandre Assunção e Silva sustenta a manutenção do direito de tudo poder pensar e dizer como um mecanismo de combate às condutas ofensivas e de tiranias à humanidade, tendo em vista que só com a liberdade de expressão é que estas poderão ser devidamente denunciadas e combatidas (SILVA, 2012, p. 11 - 12).

Para Antonio de Holanda Cavalcante Segundo, é necessário conferir a prevalência $a$ priori à liberdade de expressão, inclusive quando praticada enquanto um discurso de ódio em face de outros direitos ou valores, tendo em vista que, quando se limita esse direito, corre-se o risco de que a exceção se torne a regra, dando espaço à censura (CAVALCANTE SEGUNDO, 2016, p. 118). No entanto, ressaltam Maria Lúcia de Arruda Aranha e Maria Helena Pires Martins que, ao ser repetidamente expostos, os discursos carregados de conteúdos falsos ou até mesmo preconceituosos podem acabar sendo aceitos, equivocadamente, como verdadeiros, distanciando do que propunham os ativistas da livre e aberta atividade de expressão (ARANHA, 2009, p. 125).

A segunda corrente, favorável à restrição da liberdade de expressão, tem como um de seus expoentes Daniel Sarmento, o qual sustenta que o discurso de ódio não deve ser o meio adequado para a obtenção de respostas relacionadas a problemas que afligem a sociedade, uma vez que tal representa mais um ato hostil do que um de cunho discursivo informativo. Isso porque, diante de uma manifestação de ódio, há duas atitudes prováveis da vítima: "revidar com a mesma violência, ou retirar-se da discussão, amedrontada e humilhada. Nenhum deles contribui minimamente para 'a busca da verdade"” (SARMENTO, 2006, p. 236).

Dessa forma, ao se constatar as expressões de ódio, intolerância e preconceito manifestadas na esfera pública ou privada, mesmo quando essas estiverem sob o manto da busca da verdade e do conhecimento, é recomendável, na visão do supracitado autor, a sua proibição. De fato, o discurso em sentido estrito não deve ser considerado como a simples liberdade de 
expor “o que quiser”. Ele é uma ação com viés comunicativo que, quando assume ênfase no ato de desvalor da vítima, deixa de ser uma mera opinião, configurando-se como um discurso de incitação ao ódio, já que acarreta efeitos materiais lesivos a seus destinatários.

Para José Emílio Medauar Ommati, ao buscar negar direitos fundamentais, o discurso de ódio deixa de ser uma liberdade de expressão, razão pela qual é incabível a discussão acerca dos limites desse direito (OMMATI, 2016, p. 20 - 21).

Uma das minorias sociais mais afetadas pelo discurso de incitação ao ódio é a sexual. Apesar da história da humanidade ser marcada pela constate construção e desconstrução dos valores sexuais, hodiernamente prevalecem os fundamentos heteronormativos na condução do exercício da sexualidade humana, os quais são veiculados por meio do discurso de ódio homofóbico, que visam impor "[...] uma lógica inteligível que tenta definir o certo e o errado, o são e o patológico, o pecaminoso e o santificado" (NASCIMENTO, 2010, p. 236).

No entendimento de Thiago Dias Oliva, os atos discursivos de ódio, de cunho homofóbico, são similares aos discursos de ódio racistas, sexistas ou antissemitas, já que são comportamentos que buscam a subordinação entre dois grupos sociais. No caso em análise, essa inferiorização ocorre entre os transgressores de normas sociais relativas à sexualidade e aqueles que pretendem afirmá-las, reproduzindo e disseminando uma lógica de desumanização (OLIVA, 2015, p. 59).

Ocorre que, em inúmeras vezes, tal discurso assume um aspecto velado, como no caso de piadas ou de programas humorísticos que ridicularizam a identidade LGBT, e, em outras vezes, é perpetrado abertamente, como no caso dos discursos do deputado federal Jair Messias Bolsonaro, o qual incita, por exemplo, o estupro corretivo ${ }^{6}$, bem como a segregação das minorias sexuais (EXAME, 2016), sendo ambas as hipóteses graves e que merecem atenção e intervenção estatal.

Para identificar uma expressão homofóbica deve ser analisado seu cometimento com base na motivação a partir de características de grupos LGBT, em que mesmo que o ataque seja direcionado a uma única pessoa, quando o fator de motivação do agente for o sentimento homofóbico, isto é, aversão aos papéis culturais atribuídos ao sexo, ao gênero, à identidade de

\footnotetext{
${ }^{6} \mathrm{O}$ estupro corretivo é uma conduta ilícita, em que uma ou mais pessoas estupram mulheres homossexuais, bissexuais ou indivíduos transgêneros, visando, supostamente, "curá-los" e "corrigi-los" de suas sexualidades heto-cis-discordantes.
} 
gênero e à orientação afetivo-sexual, este ato não será um mero insulto pessoal, mas, sim, um discurso de ódio de cunho homofóbico, já que irradia seus efeitos a uma gama de vítimas.

\section{DA VIOLAÇÃO DOS DIREITOS DAS MINORIAS SEXUAIS PELO DISCURSO DE ÓDIO HOMOFÓBICO}

Um dos maiores desafios da sociedade contemporânea é estabelecer as bases para uma convivência harmônica. Buscando alcançar esse ideal, entram em cena os direitos fundamentais e de personalidade, que são faculdades atribuídas aos seres humanos para a proteção, o respeito e a promoção das necessidades relativas à vida, à liberdade, à igualdade, à participação política e social, bem como a qualquer outro aspecto essencial que afete o pleno desenvolvimento da pessoa e de sua personalidade.

Nesse sentido é que a valorização da pluralidade ganha importância, já que é um dos elementos que caracteriza o modelo da sociedade democrática brasileira. De fato, a diversidade integra o meio social e é um quesito básico para o seu progresso. Partindo desse raciocínio, a Constituição Federal, desde o seu preâmbulo, garante a liberdade, a igualdade e a justiça como valores supremos de uma sociedade fraterna, pluralista e sem preconceitos. De igual forma, vislumbra, como finalidade fundamental do Estado, a promoção do bem a todos, sem preconceitos de origem, de raça, de sexo, de cor, de idade e de quaisquer outros tipos de discriminação, conforme art. $3^{\circ}$, incs. I e IV da Constituição Federal. Ao reconhecer expressamente que todos são iguais perante a lei, sem diferenciação de qualquer natureza, preconiza a intervenção estatal a toda discriminação atentatória aos direitos e às liberdades imanentes à humanidade.

Diante desses comandos constitucionais, ao se assegurar as diferenças a partir do critério da sexualidade, em uma nação profundamente homofóbica e machista, como é a brasileira, reconhece-se que as condições sexuais de cada pessoa são fatores que a torna vulnerável. Em virtude disso, o discurso de ódio homofóbico, enquanto um instrumento veiculador da homofobia, configura-se como um dos principais meios de violar os direitos da sexualidade e das demais normas que orbitam em torno das minorias sexuais, como a vivência sexual, a identidade sexual, a autonomia sexual, a intimidade e a privacidade sexual, a integridade física e psíquica do corpo, a expressão sexual, a informação sexual livre de 
discriminações, a honra, a vida, a igualdade, a não discriminação e, sobretudo, a dignidade da pessoa humana.

Isso ocorre porque o conteúdo do discurso homofóbico, ao ser pouco a pouco difundido e assimilado como correto e coerente, reforça a intolerância contra a diversidade sexual nos diversos âmbitos institucionais do sujeito, como na família, na escola, no trabalho, instigando implícita ou explicitamente a violência na forma dos crimes de ódio. Gilmar Ferreira Mendes, nesse sentido, leciona que não se pode atribuir " [...] primazia absoluta à liberdade de expressão, no contexto de uma sociedade pluralista, em face de valores outros como os da igualdade e da dignidade humana" (MENDES, 2002).

$\mathrm{Na}$ compreensão de Samanta Ribeiro Meyer-Pflug, esse instrumento linguístico acarreta o conflito entre direitos fundamentais que constituem a própria estrutura das sociedades democráticas, “[...] pois testa a abrangência e a extensão da proteção conferida à liberdade de expressão, à dignidade da pessoa humana, aos direitos das minorias” (MEYER-PLUFG, 2009, p. 83), objetivando, exclusivamente, impor condutas anti-igualitárias e cercear a diversidade.

O discurso de ódio homofóbico, ao visar padronizar a sexualidade humana, impondoa regras para o seu exercício, legitima, de um lado, as práticas heteronormativas e, de outro, a violência simbólica ou, até mesmo, a violência direta contra as inúmeras identidades sexuais hetero-cis-discordantes. Assim, as manifestações de ódio e de repúdio a um determinado público se demonstram incompatíveis com o respeito da dignidade da pessoa humana, uma vez que tendem a reprovar e a diminuir a autoestima da vítima, bem como as reprimir de participarem livremente da vida coletiva (PRADO; JUNQUEIRA, 2011, p. 51 - 54).

Pode-se afirmar que o discurso homofóbico é um instrumento de exclusão social perante aqueles que transpõem as barreiras do modelo hetero-cisnormativo, elencado como manifestação legítima e sadia do exercício da sexualidade, razão pela qual sofrem com a discriminação, o preconceito e a exclusão social (ROCHA; CARDIN, 2015, p. 193).

Um dos direitos das minorias sexuais mais afetados pelo discurso de ódio homofóbico é o direito à vida. Certamente, esta pode ser considerada a norma mais elementar da pessoa, pois é o pressuposto para a existência e o exercício dos demais direitos e garantias. Sua proteção é um imperativo constitucional que se encontra disposto no caput do art. $5^{\circ}$ da Constituição Federal, sendo qualificado, em regra, como inviolável, intransmissível e irrenunciável. 
Para Zulmar Fachin, o direito à vida engloba a integridade física e moral do sujeito. A dimensão da integridade moral abarca os valores morais, éticos e sociais, que possibilitam a convivência deste em comunidade. Já a dimensão física se refere à inviolabilidade do corpo e de suas partes (FACHIN, 2015, p. 256 - 257).

Diante disso, a vida, enquanto um bem jurídico, deve ser compreendida em duas concepções, a primeira delas é a naturalista, a qual é puramente biológica e fisiológica (PRADO, 2011, p. 82) e tem por base a estrutura física do indivíduo, permitindo a fruição de outros direitos, já que seria impossível que outros bens jurídicos, como a sexualidade humana, existissem sem um titular (DE CUPIS, 2008, p. 72). Já em uma segunda vertente, a vida é analisada sob a concepção valorativa, devendo ser resguardada sem qualquer tipo de distinção entre seus titulares, seja por sexo, raça, gênero, orientação afetivo-sexual, idade, condições pessoais ou sociais que, conforme esclarece Luiz Regis Prado, é fruto de uma concepção filosófica personalista, a qual “[...] valoriza em primeiro lugar e acima de tudo o ser humano, como valor, pessoa e fim essencial, evitando a sua instrumentalização em função de algum interesse extra pessoal" (PRADO, 2011, p. 83).

Logo, o direito à vida vai além do seu sentido meramente biológico ou orgânico, alcançando, sobretudo, a sua dinamicidade, isto é, a sua incessantemente mutabilidade para acompanhar a esfera social de seu titular. Trata-se de uma norma tutelada de modo universal e que não pode ser interpretada de forma restrita e, sim, de modo a garantir a dignidade da pessoa humana, razão pela qual seu amparo se dá não somente pelo ordenamento jurídico brasileiro, como também por tratados e declarações internacionais, como a Declaração Universal dos Direitos Humanos ${ }^{7}$, a Convenção Americana de Direitos Humanos ${ }^{8}$, o Pacto Internacional dos Direitos Civis e Políticos ${ }^{9}$, dentre outros.

Apesar disso, é inegável que prevalece a sua inefetividade sobre as minorias sexuais, tanto pela falta de promoção de meios que as garantam uma vivência para além da trivial sobrevivência, como também pela carência legislativa de leis que proporcionem uma especial e específica atenção a esse público, que é detentor de vulnerabilidades distintas das demais minorias sociais. Nessa perspectiva, a acepção positiva do direito à vida obriga o legislador a

\footnotetext{
7 “Artigo $3^{\circ}$ Todo indivíduo tem direito à vida, à liberdade e à segurança pessoal."

8 "Artigo 4. Direito à vida. Item 1. Toda pessoa tem o direito de que se respeite sua vida. Esse direito deve ser protegido pela lei e, em geral, desde o momento da concepção. Ninguém pode ser privado da vida arbitrariamente." 9 "Artigo 6. Item 1 . O direito à vida é inerente à pessoa humana. Esse direito deverá ser protegido pela lei. Ninguém poderá ser arbitrariamente privado de sua vida."
} 
adotar medidas eficientes para protegê-la, as quais devem estar apoiadas por uma estrutura eficaz de implementação real das normas (MENDES; BRANCO, 2012, p. 382).

Ao ser analisada sob a perspectiva da sexualidade humana, a vida, em seus sentidos naturalista e valorativo, ganha um novo enfoque a partir da vivência sexual, abrangendo tanto os aspectos da integridade física da pessoa, quanto de sua integridade moral, revestindo-se como um direito correlato aos sentidos e valores sexuais. Portanto, ao desrespeitar a vida das minorias sexuais, pelo simples motivo de exercerem suas sexualidades hetero-cis-discordantes, desrespeita-se também os direitos da sexualidade humana.

Aliado à omissão estatal de combate às violências praticadas contra as pessoas LGBTs, o discurso de ódio homofóbico, por ser uma conduta repressiva, preconceituosa e estigmatizadora, cerceia o pleno exercício da sexualidade humana, na medida em que dificulta ou inviabiliza a vivência do indivíduo LGBT na sociedade. A respeito disso, de acordo com o banco de dados do Grupo Gay da Bahia (GGB), atualizado diariamente no site intitulado como "Quem a homotransfobia matou hoje?", foram registrados 318 homicídios por motivação homofóbica em território brasileiro no ano de 2015 (GRUPO GAY DA BAHIA, 2015), subindo para 343 em 2016 (GRUPO GAY DA BAHIA, 2016). Número, este, que equivale a um homicídio a cada 25 horas, em que $52 \%$ foi cometido contra gays, $37 \%$ contra transgêneros, $16 \%$ contra lésbicas, $10 \%$ contra bissexuais, $7 \%$ contra heterossexuais confundidos com gays e, por fim, $1 \%$ de companheiros transgêneros. Só nos três primeiros meses de 2017 já foram registrados 65 homicídios com o viés homofóbico (GRUPO GAY DA BAHIA, 2015).

Ainda, segundo os dados da organização não governamental (ONG) Transgender Europe (TGEU), que é uma rede europeia que luta pelos direitos da população transgênero, o Brasil ocupa o primeiro lugar nos índices de homicídios de transexuais e travestis de todo o mundo, sendo que, entre janeiro de 2008 e março de 2014, foram registradas 604 mortes no país, totalizando $50 \%$ de todos os crimes cometidos contra esse público em escala global (TGEU, 2014). Além disso, o último Relatório de Violência Homofóbica no Brasil, referente ao ano de 2013, elaborado pela Secretária Especial de Direitos Humanos e publicado somente em 2015, demonstra que, da totalidade dos atos de violência conexos com o exercício da sexualidade, $11,9 \%$ foram cometidos contra travestis e 5,9\% contra transexuais (BRASIL, 2015). 
Essas estatísticas, por mais impactantes, não representam a realidade, já que grande parte desses delitos é considerada e registrada pelos órgãos competentes como crimes comuns, sem caráter homofóbico. Fora, também, os casos de subnotificação de crimes de outra natureza, ou seja, aqueles que sequer são comunicados ao Poder Público, os quais integram a cifra negra.

Outro direito comumente violado pelo discurso do ódio homofóbico é o da igualdade. Trata-se de um direito que pode ser explorado sob dois prismas, o formal e o material. A primeira vertente, a formal, sustenta que todos devem ser tratados de modo isonômico perante a lei, sem qualquer distinção ou hierarquia (BARROSO, 2007). É a igualdade legal, aquela que se encontra disposta no caput do art. $5^{\circ}$, da Constituição Federal, ${ }^{10}$ em leis infraconstitucionais, como também em documentos internacionais, como na Declaração do Bom Povo da Virgínia de 1776 (Estados Unidos), na Declaração dos Direitos do Homem e do Cidadão de 1789 (França) e na Declaração Universal de Direitos Humanos de 1948, os quais trazem, em seus arts. $1^{\circ}$, a ideia de liberdade, igualdade e dignidade da pessoa humana, buscando impedir o favorecimento do Estado a determinado indivíduo ou grupo em detrimento dos demais. ${ }^{11}$ Refere-se, dessa forma, à aplicação do direito vigente sem distinções ou considerações de qualidades ou atributos pessoais dos destinatários da norma jurídica (RIOS, 2002, p. 33).

Nesse sentido, o Ministro do Supremo Tribunal Federal, Ayres Britto, na Ação Direita de Inconstitucionalidade n. 4277, defendeu que a diversidade sexual das pessoas, salvo expressa disposição constitucional em contrário, não deve ser um fundamento para a desigualação jurídica, isso porque o tratamento discriminatório ou desigualitário confronta com o objetivo constitucional de "promover o bem a todos" (BRASIL, 2011).

Com efeito, a utilização da igualdade em seu sentido formal, com a simples aplicação da lei ao caso concreto, não consegue atender as necessidades de grupos vulneráveis ou minorias sociais. É essencial, para Daniel Sarmento, que todas as normas sejam, ao serem aplicadas ao caso concreto, reexaminadas pelo aplicador do direito "[...] com novas lentes, que terão as cores da dignidade humana, da igualdade substantiva e da justiça social, impressas no tecido constitucional" (SARMENTO, 2010, p. 124).

\footnotetext{
10 “Art. $5^{\text {o }}$ - Todos são iguais perante a lei, sem distinção de qualquer natureza, garantindo-se aos brasileiros e aos estrangeiros residentes no País a inviolabilidade do direito à vida, à liberdade, à igualdade, à segurança e à propriedade".

11 “Art. $3^{\circ}$ Constituem objetivos fundamentais da República Federativa do Brasil: IV - promover o bem de todos, sem preconceitos de origem, raça, sexo, cor, idade e quaisquer outras formas de discriminação.”
} 
Nesse sentido, pela busca da humanização da ordem judiciária emerge a segunda dimensão do direito à igualdade: a igualdade material ou substancial, a qual estipula a igualdade de tratamento aos iguais, bem como a o desigual tratamento aos desiguais na medida de sua desigualdade. É a consideração das características subjetivas do indivíduo que confere maior efetividade a este direito, apresentando-se como uma solução para diminuir concretamente as diferenças sociais e exigindo do Poder Público medidas para a sua concretização (RIOS, 2002, p. 42).

Para José Joaquim Gomes Canotilho a igualdade não pode ser a simples aplicação positivista da lei, necessitando ser analisada em sentido material, na realização do próprio Direito, ou seja, com uma função antidiscriminatória na garantia dos direitos fundamentais de grupos minoritários (CANOTILHO, 2003, p. 381 - 386).

Este é o princípio que garante a igualdade de gêneros, de orientação afetivo-sexual, assim como de identidade de gênero, devendo garantir o respeito às demais formas de expressão da sexualidade humana, inclusive àquelas que divergem da heteronorma. No entanto, a realidade aponta para o inverso, em que a comunidade LGBT constantemente é exposta a margem da sociedade, tendo em vista que o preconceito guiado pelos atos discursivos faz com que o Estado se omita diante da degradação social que sofrem por não se encaixarem ao padrão da maioria.

De acordo com Maria Berenice Dias, enquanto houver segmentos que sejam alvo de exclusão social e tratamento desigualitário, de nada adiantará assegurar o respeito à dignidade humana e à liberdade, tendo em vista que não haverá, de fato, um Estado Democrático de Direito (DIAS, Maria Berenice, 2009, p. 359). Seguindo esse raciocínio, Geoger Marmelstein compreende que, com relação à discriminação envolvendo homossexuais, não há dispositivos legais na Constituição Federal que permita ou autorize restrições de direitos por questões de orientação afetivo-sexual (MARMELSTEIN, 2011, p. 87).

Dessa maneira, o discurso de ódio homofóbico, ao difundir a inferiorização das minorias sexuais, restringe e ofende o livre exercício da sexualidade humana, infringindo a igualdade entre as pessoas (DIAS, 2004, p. 32), já que a realização integral do ser humano somente ocorre com a preservação de sua dignidade, o que inclui sua vivência sexual (DIAS, 2011, p. 100). 
Em meio a uma sociedade multicultural e tão diversificada, Thiago Dias Oliva leciona que "[...] o discurso de ódio coloca em risco a garantia pública de inclusividade, servindo ainda como ponto de convergência para manifestações discriminatórias de indivíduos que tenham a mesma opinião do autor do discurso". Isso porque, segundo o autor, a reprodução do hate speech destrói o projeto de convivência que permite a coexistência de grupos sociais distintos de forma respeitosa, criando uma atmosfera hostil, propícia a formas ainda mais concretas de violência. (OLIVA, 2015, p. 67).

O discurso de ódio homofóbico além de ser um ato discursivo vazio de conteúdo moral, afeta a vivência e a diversidade sexual das minorias sexuais, transformando-as em indivíduos-objetos. Seus impactos são tão profundos que violam o exercício digno da sexualidade humana, o qual é um direito fundamental intrinsecamente correlato à autonomia privada, à honra e à intimidade.

Com efeito, todo ser humano é detentor de uma série de atributos subjetivos que colabora com a construção de sua identidade e de sua individualidade, fato este que implica diretamente no respeito à autodeterminação consciente e responsável da sua própria vida (MORAES, 2011, p. 48). Nessa esfera, encontra-se a liberdade sexual, que advém, segundo Maria Berenice Dias, da manifestação da autonomia de seu titular, acompanhando-o desde antes de seu nascimento até após a sua morte (DIAS, 2011, p. 99).

$\mathrm{O}$ direito à honra está previsto no art. $5^{\mathrm{a}}$, inc. X, da Constituição Federal, podendo ser dividida em honra subjetiva, que é a valoração que cada ser humano tem sobre si mesmo, e em honra objetiva, que a que faz referência à imagem e à reputação social (LORENZETTI, 1998, p. 448). O discurso de ódio homofóbico, nesse sentido, tem impacto perante a esfera da percepção que os indivíduos LGBT têm de si mesmo, afetando desde a honra objetiva como a subjetiva, tendo em vista que, mesmo quando o discurso discriminatório não é direcionado a um receptor específico, a constante reafirmação do heteroxismo contribui para que os membros das minorias sexuais e toda a sociedade assimilem essa lógica diferencialista e inferiorizante (FLEURY, 2010, p. $45-48$ ).

É uma conduta que incide também na autoestima de suas vítimas, já que, em virtude dessa inferiorização, as minorias sexuais se sentem incapazes de contribuir para o debate acerca de seus direitos e de serem ouvidas perante a sociedade, ocasionando o efeito silenciador do discurso de ódio. Acerca do tema, Owen Fiss defende que quanto mais essas pessoas são silenciadas, mais se aumenta a desigualdade e a vulnerabilidade social, tendo em vista que essa 
conduta discursiva estimula a diminuição da autoestima das vítimas, "[...] impedindo assim a sua integral participação em várias atividades da sociedade civil, incluindo o debate público. Mesmo quando estas vítimas falam, falta autoridade às suas palavras; é como se elas nada dissessem" (FISS, 2005, p. 33).

O resultado desse processo é a profunda resistência interna à aceitação dos próprios desejos, gerando distúrbios psicológicos como a depressão, a vergonha, a ansiedade e o sentimento de culpa, em outras palavras, ele cria entraves ao desenvolvimento individual e limita as potencialidades de suas vítimas, o que se dá, nos dizeres de Thiago Dias Oliva, porque "[...] senso individual de dignidade humana e de pertencimento à comunidade é ligado intimamente à preocupação e ao respeito dispensado ao grupo social ao qual o indivíduo pertence" (OLIVA, 2015, p. 62).

Outra grande violação aos direitos correlatos com a sexualidade humana permeia as esferas econômica, trabalhista e educacional. Em detrimento da constante objetificação da pessoa LGBT, com a consequente ridicularização e estigmatização de sua imagem identitária, esta tem maiores dificuldades em chegar ou permanecer no mercado de trabalho, especialmente pela baixa escolaridade, já que muitas vezes abandonam a escola precocemente em virtude do preconceito, e pela pouca qualificação (FLEURY, 2010, p. 45 - 48). Aliado a isso, a rejeição, a falta de programas sociais de acolhimento, bem como a ausência de condições financeiras para o próprio sustento contribuem para o aumento dessas pessoas à exclusão social, expondoas a viver nas ruas.

As minorias sexuais em situação de rua se tornam mais vulneráveis, especialmente os indivíduos transgêneros, sendo expostos à prostituição e ao uso de drogas para sobreviverem. Sobre o assunto, a ANTRA - Associação Nacional de Travestis e Transexuais, aponta que 90\% das travestis e transexuais estão se prostituindo no Brasil. Alerta, ainda, que mesmo que elas queiram arranjar um emprego com rotina, horário de trabalho e carteira assinada, o preconceito ofusca e inviabiliza essa alternativa (CARTA CAPITAL, 2013).

A soma da baixa escolaridade com as rejeições sociais transforma-se em obstáculos para sua empregabilidade, resultando em uma intensa presença de transexuais e travestis na informalidade, em que somente $10 \%$ das pessoas desse grupo trabalham registradas formalmente (CORREIO BRAZILIENSE, 2016). Em síntese, do ponto de vista individual, o discurso de ódio homofóbico e o medo de sua concretização em forma de violência física 
impõem limitações à liberdade aos indivíduos LGBT, regulando a maneira como essas pessoas se relacionam com o espaço público (OLIVA, 2015, p. 65).

Dessa forma, observa-se que as manifestações de opinião são essenciais para a preservação das liberdades individuais, bem como da própria democracia, no entanto, quando elas assumem uma postura vazia e ofensiva para o crescimento social, cultural, artístico ou científico, tornam-se discursos discriminatórios de ódio, funcionando como um instrumento de retaliação aos direitos das minorias sexuais.

\section{CONCLUSÃO}

A liberdade de manifestação se demonstra como um direito flexível a restrições tanto constitucionais, quanto infraconstitucionais. Em respeito ao princípio da proibição do abuso de direito, que a molda para garantir a efetividade dos demais direitos que possam ser lesados pela sua prática inconsequente, a liberdade em se expressar tem como principal limite a sua finalidade, isso porque o discurso não deve ser considerado como a simples liberdade de expor "o que quiser".

Trata-se de uma norma que tem em sua essência o caráter comunicativo que, quando assume ênfase no ato de desvalor de determinado grupo, deixa de ser uma mera opinião e se configura como um discurso de incitação ao ódio, já que busca disseminar a cultura do medo e do terror para alcançar indivíduos que, ou coadunem com esse posicionamento ou que se sintam ameaçados.

Muitas vezes, esses discursos se escondem atrás de um ilegítimo exercício da liberdade de expressão, como piadas, brincadeiras, programas de humor, etc, que, na realidade, não passa de um abuso desse direito, estando muito distante de ser uma mera opinião, já que produzem efeitos danosos às suas vítimas, como a exclusão social do ofendido.

Considerando que os direitos fundamentais e de personalidade não podem ser empregados para fins ilícitos ou moralmente injustificáveis e hostis a terceiros, o discurso de ódio homofóbico não deve ser elencado como um exercício do direito à liberdade de expressão, já que se configura como um dos principais meios de violar os direitos da sexualidade e das demais normas que orbitam as minorias sexuais, como a vivência sexual, a identidade sexual, a autonomia sexual, a intimidade e a privacidade sexual e a integridade física e psíquica do corpo. 
Além dos direitos específicos da sexualidade, o discurso de ódio homofóbico viola também os direitos correlatos com os valores sexuais, como o direito à vida, o direito à honra, a igualdade, a não discriminação e, sobretudo, a dignidade da pessoa humana. Com isso, notase que o conteúdo desse ato discursivo, ao ser pouco a pouco difundido e assimilado como correto e coerente, reforça a intolerância contra a diversidade sexual nos diversos âmbitos institucionais do sujeito, como na família, na escola, no trabalho, instigando, implícita ou explicitamente, a violência na forma dos crimes de ódio, potencializando cada vez mais a vulnerabilidade social dos indivíduos LGBTs, motivo pelo qual a sua prática deve ser suscetível de limitações.

No entanto, com a carência legislativa sobre a criminalização ou não da homofobia e das suas formas de externalidade, caberá aos operadores do direito aplicar as sanções jurídicas previstas no ordenamento jurídico brasileiro, como a responsabilização civil por danos materiais e morais, ou mesmo, em esfera criminal, com a tipificação de crimes contra a honra, contra a liberdade individual e contra vida, em conformidade com cada bem jurídico violado das minorias sexuais.

\section{REFERÊNCIAS}

AMATO, Lucas Fucci. Abuso de direitos fundamentais, pluralismo cultural e critérios de tratamento igual. Revista do Observatório da Jurisdição Constitucional, Instituto Brasiliense de Direito Público, ano 6, n. 2, jul./dez. 2013. Disponível em: <https://www.portaldeperiodicos.idp.edu.br/observatorio/article/viewFile/871/612>. Acesso em: 17 fev. 2017.

ARANHA, Maria Lúcia de Arruda; MARTINS, Maria Helena Pires. Filosofando: Introdução à Filosofia. 4. ed. São Paulo: Moderna, 2009.

BARROSO, Luís Roberto. Diferentes, mas Iguais: o reconhecimento jurídico das relações homoafetivas no Brasil. Revista Diálogo Jurídico, Salvador, v. 2, n. 16, p. 1 - 32, ago. 2007. Disponível em:

<http://www.direitopublico.com.br/pdf_seguro/diferentes_iguais_lrbarroso.pdf $>$. Acesso em: 08 fev. 2017.

BERLIN, Isaiah. Quatro ensaios sobre a liberdade. Trad. Wamberto Hudson Ferreira. Brasília: UnB, 1981. 
BRASIL, Secretaria Especial de Direitos Humanos. Relatório de Violência Homofóbica no Brasil: ano 2013. 2015. Disponível em: <http://www.sdh.gov.br/assuntos/lgbt/dadosestatisticos/Relatorio2013.pdf>. Acesso em: 17 fev. 2017.

BRASIL. Decreto n. 592, de 6 de julho de 1992: Pacto Internacional sobre Direitos Civis e Políticos. 1992. Disponível em: <www.planalto.gov.br/ccivil_03/decreto/19901994/d0592.htm>. Acesso em: 17 fev. 2017.

BRASIL. Supremo Tribunal Federal. Voto. Relator: Ministro Ayres Britto. Ação Direta de Inconstitucionalidade $n^{o}$ 4277. 2011. Disponível em:

<http://www.stf.jus.br/arquivo/cms/noticiaNoticiaStf/anexo/ADI4277revisado.pdf>. Acesso em: 13 fev. 2017.

BRUGGER, Winfried. Proibição ou proteção do discurso do ódio? Algumas observações sobre o direito alemão e o americano. Revista de Direito Público, Brasília, v. 15, n. 117, jan./mar. 2007.

CANOTILHO, José Joaquim Gomes. Direito Constitucional e teoria da Constituição. 7. ed. Coimbra: Livraria Almedina, 2003.

CARDIN, Valéria Silva Galdino; SANTOS, Andréia Colhado Gallo Grego Santos. Liberdade de expressão versus dignidade da pessoa humana: considerações sobre o discurso de ódio contra a mulher na internet e seus efeitos. Anais do XXIII Congresso Nacional do CONPEDI, João Pessoa, Pernambuco, p. 169 - 190, nov., 2014. Disponível em: <publicadireito.com.br/artigos/?cod=e353194f3b7cd1b7>. Acesso em: 17 fev. 2017. ; CAZELATTO, Caio Eduardo Costa. Da vulnerabilidade social das minorias sexuais sob a perspectiva jurídica. In: CAMPOS, Nilson Tadeu Reis. (Org.). O direito e as pessoas vulneráveis na contemporaneidade. Rio de Janeiro: Lumen Juris, 2016.

; SEGATTO, Antonio Carlos; CAZELATTO, Caio Eduardo Costa Cazelatto. O exercício ilegítimo do discurso de ódio homofóbico sob a ótica da sexualidade e da dignidade humana. Revista Jurídica Unicuritiba, Curitiba, v. 1, n. 46, p. 90-118, 2017. ISSN: 2316753X. Disponível em:

<http://revista.unicuritiba.edu.br/index.php/RevJur/article/view/2001/1282>. Acesso em: 04 out. 2017.

CARTA CAPITAL. O preconceito contra transexuais no mercado de trabalho. 2013. Disponível em: <www.cartacapital.com.br/blogs/feminismo-pra-que/o-preconceito-contratransexuais-no-mercado-de-trabalho-2970.html>. Acesso em: 11 nov. 2016.

CAVALCANTE SEGUNDO, Antonio de Holanda. Uma questão de opinião? Liberdade de expressão e seu âmbito protetivo: da livre manifestação do pensamento ao Hate Speech. Rio de Janeiro: Lumen Juris, 2016.

CAZELATTO, Caio Eduardo Costa; CARDIN, Valéria Silva Galdino. Dos impactos do discurso de ódio homofóbico no ambiente informático. Revista de Direito, Governança e Novas Tecnologias, Brasília, n. 1, v. 3, p. 1-22, jan./jun. 2017. ISSN: 2526-0049. Disponível em: <indexlaw.org/index.php/revistadgnt/article/view/1947/pdf>. Acesso em: 07 dez. 2017. 
; __ Dos aspectos jurídicos da pedofilia: por uma intervenção estatal digna e efetiva ao pedófilo. Revista Quaestio Iuris, Rio de Janeiro, v. 10, n. 04, p. 2863-2876, 2017. ISSN: 1516-0351. Disponível em: <www.epublicacoes.uerj.br/index.php/quaestioiuris/article/view/26686/21927>. Acesso em 19 dez. 2017.

; $ـ$ Homophobic hate discourse in the information society: from the impacts to the balance of the computer environment and to human sexuality. Revista do Direito UNISC, Santa Cruz do Sul, v. 1, n. 51, p. 176-191, jan. 2017. ISSN 1982-9957. Disponível em: <https://online.unisc.br/seer/index.php/direito/article/view/8742>. Acesso em: 04 out. 2017.

; __ O discurso de ódio homofóbico no Brasil: um instrumento limitador da sexualidade humana. Revista Jurídica Cesumar - Mestrado, Maringá, v. 16, n. 3, p. 919-938, set./dez. 2016. ISSN 2176-9184. Disponível em:

<periodicos.unicesumar.edu.br/index.php/revjuridica/article/view/5465/2893>. Acesso em: Acesso em: 04 out. 2017.

COMPARATO, Fábio Konder. A afirmação histórica dos direitos fundamentais. 5. ed. São Paulo: Saraiva, 2007.

CORREIO BRAZILIENSE. Desafio dos transexuais no mercado de trabalho é a baixa escolaridade. 2016. Disponível em:

<www.correiobraziliense.com.br/app/noticia/cidades/2016/05/18/interna_cidadesdf,532398/d esafio-dos-transexuais-no-mercado-de-trabalho-e-a-baixa-escolaridade.shtml $>$. Acesso em: 11 nov. 2016.

CUNDARI, Paula Casari. Limites da liberdade de expressão: Imprensa e Judiciário no "Caso Editora Revisão". Tese (Doutorado em Comunicação Social) - Pontifícia Universidade Católica do Rio Grande do Sul, Porto Alegra, 2006.

DE CUPIS, Adriano. Os direitos da personalidade. 2. ed. Trad. Afonso Celso Furtado Rezende. São Paulo: Quorum, 2008.

DIAS, Maria Berenice. Conversando sobre a homoafetividade. Porto Alegre: Livraria do Advogado, 2004.

DIAS, Maria Berenice. Homoafetividade e Direito Homoafetivo. In: DIAS, Maria Berenice; BASTOS, Eliene Ferreira; MORAES, Naime Márcio Martins (coord.). Afeto e estruturas familiares. Belo Horizonte: Del Rey, 2009.

DIAS, Maria Berenice. União homoafetiva: o preconceito \& a justiça. 5. ed. São Paulo: Revista dos Tribunais, 2011.

DWORKIN, Ronald. $O$ direito da liberdade: A leitura moral da Constituição norte americana. São Paulo: Martins Fontes, 2006. 
EXAME. Jair Bolsonaro reforça homofobia em entrevista a Ellen Page. 2016. Disponível em: <exame.abril.com.br/brasil/jair-bolsonaro-reforca-homofobia-em-entrevista-a-ellenpage/>. Acesso em: 12 fev. 2017.

FACHIN, Zulmar. Curso de Direito Constitucional. 7. ed. Rio de Janeiro: Forense, 2015.

FERMENTÃO, Cleide Aparecida Gomes Rodrigues Fermentão. Direito à liberdade: Por um paradigma de essencialidade que dê eficácia ao Direito Personalíssimo da Liberdade.

Curitiba: Juruá, 2009.

FISS. Owen M. A Ironia da Liberdade de Expressão: Estado, Regulação e Diversidade na Esfera Pública. Trad. Gustavo Binembojm e Caio Mário da Silva Pereira Neto. Rio de Janeiro: Renovar, 2005.

FIUZA, César. Direito civil: curso completo. 8. ed. Belo Horizonte: Del Rey, 2004.

FLEURY, Alessandra Ramos Demito. Homossexualidade e preconceito: o que pensam os futuros gestores de pessoas. Curitiba: Juruá, 2010.

FREITAS, Riva Sobrado de; CASTRO, Matheus Felipe de. Liberdade de Expressão e Discurso do Ódio: um exame sobre as possíveis limitações à liberdade de expressão. Revista Sequência, Florianópolis, n. 66, p. 327 - 355, jul. 2013. Disponível em:

$<$ https://periodicos.ufsc.br/index.php/sequencia/article/view/2177-

7055.2013v34n66p327/25072>. Acesso em: 17 fev. 2017.

GRUPO GAY DA BAHIA. Quem a homotransfobia matou hoje?. Disponível em: <https://homofobiamata.wordpress.com/estatisticas/relatorios/2015-2/>. Acesso em: 04 mar. 2017.

GRUPO GAY DA BAHIA. Relatório 2015: Assassinatos de LGBT no Brasil. 2015. Disponível em: <www.calameo.com/read/0046502184820246ba018>. Acesso em: 17 fev. 2017.

GRUPO GAY DA BAHIA. Relatório 2016: Assassinatos de LGBT no Brasil. 2016. Disponível em: <https://homofobiamata.files.wordpress.com/2017/01/relatc3b3rio-2016ps.pdf>. Acesso em: 17 fev. 2017.

JABUR, Gilberto Haddad. Liberdade de pensamento e direito à vida privada: conflitos entre direitos da personalidade. São Paulo: Revista dos Tribunais, 2000.

LORENZETTI, Luis Ricardo.Fundamentos do direito privado. Trad. Vera Maria Jacob de Fradera. São Paulo: Revista dos Tribunais, 1998.

MARMELSTEIN, George. Curso de Direitos Fundamentais. 3 ed. São Paulo: Atlas, 2011.

MELLO FILHO, José Celso de. Constituição Federal anotada. 2. ed. São Paulo: Saraiva, 1986. 
MENDES, Gilmar Ferreira. A Jurisdição constitucional no Brasil e seu significado para a liberdade e a igualdade. 2002. Disponível em

$<$ http://www.stf.jus.br/arquivo/cms/noticiaArtigoDiscurso/anexo/munster_port.pdf $>$. Acesso em: 12 fev. 2017.

MENDES, Gilmar Ferreira; BRANCO, Paulo Gustavo Gonet. Curso de direito constitucional. 7. ed. São Paulo: Saraiva, 2012.

MEYER-PLUFG, Samantha Ribeiro. Ideias devem ser confrontadas com ideias. Revista Problemas Brasileiros, SESC, São Paulo, n. 406, jul./ago., 2011. Disponível em:

$<$ https://www.sescsp.org.br/online/artigo/6041_liberdade+de+expressao>. Acesso em: $17 \mathrm{fev}$. 2017.

MEYER-PLUFG, Samantha Ribeiro. Liberdade de expressão e discurso do ódio. São Paulo: Revista dos Tribunais, 2009.

MEYER-PLUFG, Samantha Ribeiro; CARCARÁ, Thiago Anastácio. Discurso de ódio e democracia: participação das minorias na busca pela tolerância. Anais do XXIII Encontro Nacional do CONPEDI, Florianópolis, Santa Catarina, p. 373 - 398, mai., 2014.

MILL, John Stuart. Sobre a liberdade. Trad. Alberto da Rocha Barros. Rio de Janeiro: Vozes, 1992.

MORAES, Alexandre de. Direitos humanos fundamentais: teoria geral, comentários aos arts. $1^{\circ}$ a $5^{\circ}$ da Constituição da República Federativa do Brasil, doutrina e jurisprudência. 9. ed. São Paulo: Atlas, 2011.

NADER, Paulo. Curso de Direito Civil: Parte Geral. 10. ed. Rio de Janeiro: Forense, v. 1.

NASCIMENTO, Márcio Alessandro Neman do. Homofobia e homofobia interiorizada: produções subjetivas de controle heteronormativo? Revista Athenea Digital, n. 17, p. 227 239, mar. 2010. Disponível em<http://atheneadigital.net/article/download/n17nascimento/652-pdf-pt>. Acesso em: 17 fev. 2017.

OLIVA, Thiago Dias. Minorias sexuais e os limites da liberdade de expressão: o discurso de ódio e a segregação social dos indivíduos LGBT no Brasil. Curitiba: Juruá, 2015.

OMMATI, José Emílio Medauar. Liberdade de expressão e discurso de ódio na Constituição de 1988. 3. ed. Rio de Janeiro: Lumen Juris, 2016.

PRADO, Luiz Regis. Curso de Direito Penal Brasileiro: parte especial, arts. 121 a 249. 10. ed. São Paulo: Revista dos Tribunais, 2011, v. 2.

PRADO, Marco Aurélio Máximo; JUNQUEIRA, Rogério Diniz. Homofobia, hierarquização e humilhação social. In: VENTURI, Gustavo; BOKANY, Vilma (Orgs.). Diversidade sexual e homofobia no Brasil. São Paulo: Fundação Perseu Abramo, 2011. 
RAO, Vicente. O direito e a vida dos direitos. São Paulo: Revista dos Tribunais, 1999.

RIOS, Roger Raupp. O princípio da igualdade e a discriminação por orientação sexual: a homossexualidade no direito brasileiro e norte-americano. São Paulo: Revista dos Tribunais, 2002.

ROCHA, Francielle Lopes; CARDIN, Valéria Silva Galdino. Do discurso do ódio contra as minorias sexuais como um instrumento de exclusão social. In: SIQUEIRA, Dirceu Pereira; AMARAL, Sérgio Tibiriça (org.). Democracia, Liberdade e Justiça Social: Fundamentos para uma teoria jurídica do reconhecimento. Biriqui: Boreal, 2015.

ROLIM. Convenção Americana Sobre Direitos Humanos. 1966. Disponível em: <www.rolim.com.br/2002/_pdfs/pactoSanJose.pdf>. Acesso em: 02 out. 2016.

ROUSSEAU, Jean-Jacques. Do contrato social: princípios do direito político. São Paulo: CD, 2001.

SARMENTO, Daniel. Livres e Iguais: Estudos de Direito Constitucional. Rio de Janeiro: Lumen Juris, 2006.

SARMENTO, Daniel. Direitos Fundamentais e Relações Privadas. 2. ed. Rio de Janeiro: Lumen Juris, 2010.

SILVA, Alexandre Assunção e. Liberdade de expressão e crimes de opinião. São Paulo: Atlas, 2012.

SILVA, José Afonso da. Curso de direito constitucional positivo. 37. ed. Malheiros, 2014.

SILVA, Rosane Leal da; et al. Discursos de ódio em redes sociais: jurisprudência brasileira. Revista Direito Projeto gráfico, São Paulo, n. 7, p. 445 - 468, jul/dez. 2011.

SILVEIRA, Renata Machado da. Liberdade de expressão e discurso do ódio. Dissertação (Mestrado em Direito) - Pontifícia Universidade Católica de Minas Gerais, Belo Horizonte, 2007.

TAVARES, André Ramos. Liberdade de expressão: comunicação em face do direito à privacidade. In: MARTINS, Ives Granda da Silva; PEREIRA JUNIOR, Antônio Jorge (Coords.). Direito à privacidade. São Paulo: Ideias \& Letras, 2005.

TGEU, Transgender Europe. Transgender Europe's Trans Murder Monitoring project reveals. 2014. Disponível em: <http://tgeu.org/transgender-europe-tdor-press-release-october30-2014/>. Acesso em: 11 nov. 2016.

UNITED NATIONS HUMA RIGHTS. Declaração Universal dos Direitos Humanos. 1948. Disponível em: <www.ohchr.org/EN/UDHR/Documents/UDHR_Translations/por.pdf>. Acesso em: 02 out. 2016. 
VANEIGEM, Raoul. Nada é sagrado, tudo pode ser dito: Reflexões sobre a liberdade de expressão. Trad. Marcos Marcionilo. São Paulo: Parábola Breve, 2004. 